\title{
inu \\ Effects of Co Doping on the Growth and Photocatalytic Properties of ZnO Particles
}

\author{
Lanqin Tang ${ }^{1,2,3, *}$, Yin Jia ${ }^{1}$, Zhishang Zhu ${ }^{1}$, Yue Hua ${ }^{1}$, Jun Wu ${ }^{1}$, Zhigang Zou ${ }^{2,3}$ and Yong Zhou ${ }^{2,3, *}$ \\ 1 College of Chemistry and Chemical Engineering, Yancheng Institute of Technology, 9 Yingbin Avenue, \\ Yancheng 224051, China; xiaoyu2898@sina.com (Y.J.); DouglasM2000@163.com (Z.Z.); \\ JoannaVu22@163.com (Y.H.); swujun@163.com (J.W.) \\ 2 National Laboratory of Solid State Microstructures, Collaborative Innovation Center of Advanced Microstructures, \\ School of Physics, Nanjing University, Nanjing 210093, China; zgzou@nju.edu.cn \\ 3 Eco-Materials and Renewable Energy Research Center (ERERC), Nanjing University, Nanjing 210093, China \\ * Correspondence: lanqin_tang@163.com (L.T.); zhouyong1999@nju.edu.cn (Y.Z.)
}

check for updates

Citation: Tang, L.; Jia, Y.; Zhu, Z.; Hua, Y.; Wu, J.; Zou, Z.; Zhou, Y. Effects of Co Doping on the Growth and Photocatalytic Properties of $\mathrm{ZnO}$ Particles. Molecules 2022, 27, 833. https://doi.org/10.3390/molecules 27030833

Academic Editor: Hongda Li

Received: 13 January 2022

Accepted: 25 January 2022

Published: 27 January 2022

Publisher's Note: MDPI stays neutral with regard to jurisdictional claims in published maps and institutional affiliations.

Copyright: (C) 2022 by the authors. Licensee MDPI, Basel, Switzerland. This article is an open access article distributed under the terms and conditions of the Creative Commons Attribution (CC BY) license (https:// creativecommons.org/licenses/by/ $4.0 /)$.

\begin{abstract}
The present work reports on the synthesis of $\mathrm{ZnO}$ photocatalysts with different Co-doping levels via a facile one-step solution route. The structural and optical properties were characterized by powder X-ray diffraction (XRD), field emission scanning electron microscopy (FESEM), transmission electron microscopy (TEM), energy dispersive spectroscopy (EDS), and UV-Vis diffuse reflectance spectra. The morphology of Co-doped $\mathrm{ZnO}$ depends on the reaction temperature and the amount of $\mathrm{Co}$ and counter-ions in the solution. Changes with the c-axis lattice constant and room temperature redshift show the replacement of $\mathrm{Zn}$ with Co ions without changing the wurtzite structure. Photocatalytic activities of Co-doped $\mathrm{ZnO}$ on the evolution of $\mathrm{H}_{2}$ and the degradation of methylene blue $(\mathrm{MB})$ reduce with the doping of Co ions. As the close ionic radii of $\mathrm{Co}$ and $\mathrm{Zn}$, the reducing photocatalytic activity is not due to the physical defects but the formation of deep bandgap energy levels. Photocurrent response experiments further prove the formation of the recombination centers. Mechanistic insights into $\mathrm{Co}-\mathrm{ZnO}$ formation and performance regulation are essential for their structural adaptation for application in catalysis, energy storage, etc.
\end{abstract}

Keywords: $\mathrm{ZnO}$; Co-doped; flower-like; photocatalytic properties; chemical method

\section{Introduction}

The photocatalytic transformation has received continuous attention with the depletion of fossil fuels and the intensification of environmental pollution [1]. Traditional semiconductors, such as $\mathrm{TiO}_{2}, \mathrm{ZnO}$, etc., are usually applied as photocatalysts [2]. Controlling the morphologies of catalysts with specific exposed facets will result in efficient separation of the electron-hole pairs [3]. Doping ions is an effective way to reduce the bandgap of catalysts and improve the ability of visible-light harvesting [4,5]. Consequently, considerable interest has been focused on synthesizing photocatalysts with controllable morphologies and regulating their photocatalytic properties by a doping-based method.

Zinc oxide $(\mathrm{ZnO})$ has been actively investigated due to its unique optical, electronic, and piezoelectric properties, such as solar cells [6], piezotronics [7], UV detectors [8], gas sensors [9], and light-emitting diodes (LEDs) [10]. Additionally, $\mathrm{ZnO}$ is a promising semiconductor with the richest range of morphologies and has been found to display good photoconductivity and high transparency in the visible region [11]. There are several methods available for controlling morphologies at present, such as the sputtering deposition technique [12], chemical vapor deposition [13], pulsed laser deposition [14], and the coprecipitation process [15]. Among these methods, the aqueous solution method appears more favorable in an economical and large-scale production [16-18]. Particles with specific crystal facets and complex corrugated particles with tips also have good photocatalytic activity and dispersion properties [19-22]. Based on previous studies, the microstructure, 
morphology, and luminescence performance of particles are extremely sensitive to the conditions of their preparation.

The Co-doping element is of much interest among the transition metal ions. Substituting the non-magnetic element $\mathrm{Zn}$ ion with the Co ion can introduce ferromagnetic behavior while retaining its semiconducting properties. There were also some reports on Co-doped $\mathrm{ZnO}$ nanoparticles, such as nano-crystalline powders [23], nanowires [24], etc. Different methods were applied to prepare Co-doped $\mathrm{ZnO}$ particles. For example, Chang et al. use the solvothermal method and calcination to dope $\mathrm{Co}^{2+} / \mathrm{Co}^{3+}$ ions [25]. A similar process conducted at $150{ }^{\circ} \mathrm{C}$ is also reported by Fang and Wang et al. [26]. Asif et al. reported bimetallic $\mathrm{Co}-\mathrm{Ni} / \mathrm{ZnO}$ cubes through the hydrothermal process [27]. It is suggested that structural, optical, and photocatalytic properties largely depended on the synthesis method. The aqueous solution method is more facile for regulating the structures of catalysts, which influence their properties. Furthermore, previous applications mainly focus on sensing, Raman, magnetism, and antibacterial activity. Therefore, it seems necessary to study the growth parameters and Co-dopant effects on the photocatalytic activity of the Co-doped $\mathrm{ZnO}$.

A simple one-step aqueous solution route is reported for synthesizing Co-doped $\mathrm{ZnO}$ nanoparticles. No organic solvents or high-temperature treatments are used. The presented doping process has been achieved at an attractive low temperature $\left(50^{\circ} \mathrm{C}\right)$. Well-defined flower-like $\mathrm{ZnO}$ and $\mathrm{Co}-\mathrm{ZnO}$ particles have been directly obtained. The present work investigates the formation process and photocatalytic activities of pure and cobalt-doped $\mathrm{ZnO}$ nanoparticles. It is worth noting that we used the Co-doped $\mathrm{ZnO}$ structure as a model system to understand the growth and doping-induced photocatalytic property mechanism. Effects of growth parameters such as doping content, reaction temperature, and counter-ions on the formation of particles are studied. The influences of Co-doping on structural, optical, morphological, and photocatalytic activities, including methylene blue degradation and $\mathrm{H}_{2}$ evolution, are also investigated in detail. Due to the similar ionic radii of $\mathrm{Co}$ and $\mathrm{Zn}$, the replacement of $\mathrm{Zn}$ with Co creates deep bandgap levels and acts as the recombination centers, and eventually leads to the reduction of the photocatalytic activity. Therefore, doping species should be paid more attention. This method opens a new avenue for regulating the microstructure and properties of photocatalytic inorganic compounds.

\section{Experimental}

\subsection{Materials}

The starting chemical reagents used in this work were: zinc acetate dihydrate $\left(\mathrm{Zn}\left(\mathrm{CH}_{3} \mathrm{COO}\right)_{2} \cdot 2 \mathrm{H}_{2} \mathrm{O}\right)$, cobaltous chloride hexahydrate $\left(\mathrm{CoCl}_{2} \cdot 6 \mathrm{H}_{2} \mathrm{O}\right)$, cobalt acetate tetrahydrate $\left(\mathrm{Co}\left(\mathrm{CH}_{3} \mathrm{COO}\right)_{2} \cdot 4 \mathrm{H}_{2} \mathrm{O}\right)$, and sodium hydroxide $(\mathrm{NaOH})$, all of which were from Sinopharm Chemical Reagent Co., Ltd., Shanghai, China, and were used as analytic grade without further purification.

\subsection{Experimental Procedure}

In a typical synthesis, $50 \mathrm{~mL}$ of a mixed solution containing $0.05 \mathrm{~mol}$ of $\mathrm{Zn}\left(\mathrm{CH}_{3} \mathrm{COO}\right)_{2} \cdot 2 \mathrm{H}_{2} \mathrm{O}$ and a certain amount of $1.0 \mathrm{M} \mathrm{CoCl}_{2} \cdot 6 \mathrm{H}_{2} \mathrm{O}$ solution were prepared in a three-necked flask under stirring. Then, $50 \mathrm{~mL}$ of $2.0 \mathrm{M} \mathrm{NaOH}$ solution was added dropwise to the flask at a rate of $1.0 \mathrm{~mL} / \mathrm{min}$ at $50{ }^{\circ} \mathrm{C}$, resulting in the formation of precipitates. After adding the above-mixed solution, the obtained precipitates were washed with distilled water and dried at $70{ }^{\circ} \mathrm{C}$ in the air for $24 \mathrm{~h}$. The molar ratio of $\mathrm{Co}^{2+} / \mathrm{Zn}^{2+}, \mathrm{R}$, was varied from 0.2:100 to $0.8: 100$. Experimental conditions for typical Co-doped $\mathrm{ZnO}$ samples are listed in Table 1.

\subsection{Characterization of Materials}

The crystalline structures were characterized using a Rigaku D/Max-RA Cu K $\alpha$ diffractometer employing a scanning rate of $0.01^{\circ} \mathrm{S}^{-1}$ in the $2 \theta$ ranges from 30 to $70^{\circ}$. Zinc oxide crystallites were quantitatively characterized and compared with the calculated texture coefficient, $T_{\mathrm{c}(\mathrm{hkl})}$. The texture coefficient, $T_{\mathrm{c}(\mathrm{hkl})}$, is defined as follows [28]: $T_{\mathrm{c}(\mathrm{hkl})}=$ 
$\left(I_{(\mathrm{hkl})} /{ }_{\mathrm{Ir}(\mathrm{hkl})}\right) /\left[1 / n \Sigma\left(I_{(\mathrm{hkl})} / I_{\mathrm{r}(\mathrm{hkl})}\right)\right]$, where $T_{\mathrm{c}(\mathrm{hkl})}$ is the texture coefficient, $n$ is the number of peaks considered, $I_{(\mathrm{hkl})}$ are the intensities of the peaks of obtained zinc oxide samples, and $I_{\mathrm{r}(\mathrm{hkl})}$ is the peak intensities indicated in the JCPDS 36-1451 corresponding to the randomly oriented crystallites. The lattice parameter, $\mathrm{c}$, of the samples is calculated using the formula: $\sin ^{2} \theta=\lambda^{2} / 4\left[4\left(h^{2}+h k+k^{2}\right) / 3 a^{2}+l^{2} / c^{2}\right]$, where $\theta$ is the diffraction angle, $\lambda$ is the incident wavelength, and $h, k$, and $l$ are all Miller's indices. The morphologies of the samples were studied by field emission scanning electron microscope (FESEM, JEOL JSM-6700F, Tokyo, Japan) and a transmission electron microscope (TEM, JEOL-1230, Tokyo, Japan). Energy dispersive spectroscopy (EDS) measurements were applied to determine the dopant content of cobalt ions in the $\mathrm{Co}-\mathrm{ZnO}$ particles. The response curves were measured with the light on/off cycles at $0 \mathrm{~V}$ versus SEC (saturated calomel electrode).

Table 1. Preparation parameters of various Co-doped $\mathrm{ZnO}$ samples.

\begin{tabular}{|c|c|c|c|c|c|}
\hline Samples & Morphology & $\mathrm{Zn}^{2+}(\mathrm{mL})$ & $\mathrm{Co}^{2+}(\mathrm{mL})$ & $\begin{array}{c}\mathrm{Co} / \mathrm{Zn} \\
\text { (Theoretical Zn, mol \%) }\end{array}$ & $\begin{array}{c}\text { Reaction } \\
\text { Temperature }\left({ }^{\circ} \mathrm{C}\right)\end{array}$ \\
\hline $\mathrm{S}_{0}$ & OLP & 50 & 0.00 & 0 & 50 \\
\hline $\mathrm{S}_{0.2}$ & OLP & 50 & 0.10 & $0.2: 100$ & 50 \\
\hline $\mathrm{S}_{0.4}$ & OLP & 50 & 0.20 & $0.4: 100$ & 50 \\
\hline $\mathrm{S}_{0.6}$ & FLP & 50 & 0.30 & $0.6: 100$ & 50 \\
\hline $\mathrm{S}_{0.8}$ & FLP & 50 & 0.40 & $0.8: 100$ & 50 \\
\hline $\mathrm{S}_{0}{ }^{*}$ & NR & 50 & 0.00 & 0 & 70 \\
\hline $\mathrm{S}_{0.2^{*}}$ & NR & 50 & 0.10 & $0.2: 100$ & 70 \\
\hline $\mathrm{S}_{0.8}{ }^{*}$ & NR & 50 & 0.40 & $0.8: 100$ & 70 \\
\hline
\end{tabular}

OLP, NR, and FLP are abbreviations describing product morphology and refer to olive-like particles, nanorods, and flower-like particles, respectively.

\subsection{Measurement of Photocatalytic Activity}

Methylene Blue (MB) dye was used to evaluate the photocatalytic activity of doped and pure $\mathrm{ZnO}$ particles in response to UV light. A $6 \mathrm{~W}$ UV lamp with a wavelength of $365 \mathrm{~nm}$ was employed as the light source. Then, $50 \mathrm{mg}$ of photocatalysts was dispersed in $100 \mathrm{~mL}$ of $10 \mathrm{mg} / \mathrm{L}$ of the $\mathrm{MB}$ aqueous solution in a $100 \mathrm{~mL}$ beaker. The suspension was stirred in the dark for $30 \mathrm{~min}$ to ensure the adsorption and desorption equilibrium of MB on the particle surface. Subsequently, the suspension was irradiated with simulated UV light. The distance between the light source and the surface of the solution was $6 \mathrm{~cm}$. After every $30 \mathrm{~min}$ of irradiation, $5 \mathrm{~mL}$ of the suspension was extracted and then centrifuged to separate particles from the supernatant. The obtained solution was analyzed by recording variations in the absorption band $(663 \mathrm{~nm})$ in the UV-Vis spectra of MB using a UV-2100 spectrophotometer.

Photocatalytic activity in $\mathrm{H}_{2}$ production was examined using a $100 \mathrm{~mL}$ Pyrex flask. The flask was sealed with a silicone rubber septum. A $300 \mathrm{~W}$ Xe arc lamp was used as the light source. In a typical experiment, $50.0 \mathrm{mg}$ of photocatalyst was mixed in $100 \mathrm{~mL}$ of an aqueous solution containing $0.25 \mathrm{M} \mathrm{NaS}_{2}$ and $0.25 \mathrm{M} \mathrm{NaSO}_{3}$. Before irradiation, the suspension was bubbled with nitrogen for $30 \mathrm{~min}$ to remove any dissolved oxygen and ensure the system was under anaerobic conditions. Magnetic stirring was used throughout the reaction to keep the photocatalyst particles in a suspension state. In addition, $0.4 \mathrm{~mL}$ of gas was sampled intermittently through the septum and analyzed using a gas chromatograph equipped with a thermal conductivity detector (TCD).

\section{Results and Discussion}

\subsection{Structural and Morphological Characteristics}

Cobalt was selected for its expected ease in doping due to the similar ionic radius $(0.58 \AA)$ to $\mathrm{Zn}(0.60 \AA)$. Figure 1 displays XRD patterns of pure $\mathrm{ZnO}$ powder (sample- $\left.\mathrm{S}_{0}\right)$, Codoped sample-S0.2, and sample-S0.8 photocatalysts. In each case, the characteristic (100), (002), (101), (102), (110), (103), (200), (112), and (201) reflections of simple wurtzite phase 
(ZnO, JCPDS No.36-1451) were observed, and no XRD patterns arising from other phases appeared. The XRD patterns of Co-doped $\mathrm{ZnO}$ samples show the same characteristics as undoped $\mathrm{ZnO}$, consisting of only peaks corresponding to $\mathrm{ZnO}$. This is because XRD has a relatively poor detection limit of around $1 \%$ by volume. The sharp and intense peaks in these structures indicate that all samples are highly crystallized. There is a reduction of the c-axis lattice constants with the increase of Co-dopant level, to $5.2091 \AA$ (sample- $S_{0}$ ), $5.2086 \AA$ (sample-S0.2), and $5.2079 \AA$ (sample-S0.8). Since the difference in radii of Co and $\mathrm{Zn}$ is minimal, the changes in cell parameters with cobalt substitution in the lattice are rather small [28]. Therefore, the difference of lattice parameters could be attributed to Co incorporation, which indicates defect evolution in the lattice.

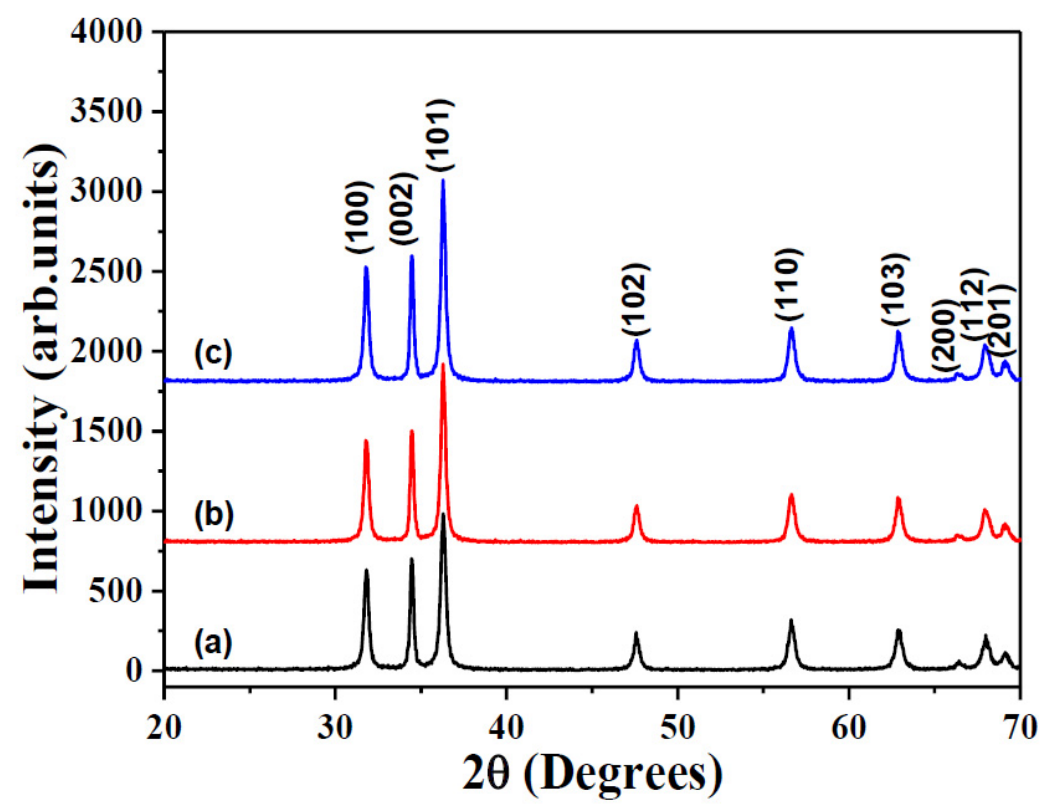

Figure 1. The powder XRD patterns of pure $\mathrm{ZnO}$ sample- $\mathrm{S}_{0}(\mathbf{a})$, sample-S0.2 (b), and sample-S0.8 (c) photocatalysts.

The texture coefficient values of these samples produced in the presence or the absence of Co were also calculated according to their three main corresponding X-ray diffraction peaks (Table 2). The (002) orientation with a high texture coefficient, $T_{\mathrm{c}(002)}$, is stronger than the (100) orientation and the (101) orientation. $T_{\mathrm{c}(\mathrm{hkl})}$ of 1 presents a sample with randomly oriented crystallites, where a larger value indicates an abundance of crystallites oriented to the $(h k l)$ plane [29]. These results confirmed that the addition of Co did not change the (002) growth direction. Furthermore, with the loading of $\mathrm{Co}$, the average crystal size of these samples decreased from $28.78 \mathrm{~nm}$ (sample-S $)_{0}$ ) to $14.39 \mathrm{~nm}$ (sample-S0.2) and $5.08 \mathrm{~nm}$ (sample-S0.8). Co led to a smaller crystal size of the produced zinc oxide particles.

Table 2. Texture coefficients of the obtained $\mathrm{ZnO}$ samples with different amounts of Co.

\begin{tabular}{ccccc}
\hline \multirow{2}{*}{ Samples } & $\mathbf{M}_{\mathbf{C o}}{ }^{2+}: \mathbf{M}_{\mathbf{Z n}}{ }^{2+}$ & \multicolumn{3}{c}{ Texture Coefficient } \\
\cline { 3 - 5 } & $0: 100$ & $\boldsymbol{T}_{\mathbf{c}(\mathbf{1 0 0})}$ & $\boldsymbol{T}_{\mathbf{c}(\mathbf{0 0 2})}$ & $\boldsymbol{T}_{\mathbf{c}(\mathbf{1 0 1})}$ \\
\hline $\mathrm{S}_{0}$ & $0.2: 100$ & 0.91 & 1.29 & 0.80 \\
$\mathrm{~S}_{0.2}$ & $0.6: 100$ & 0.87 & 1.24 & 0.89 \\
$\mathrm{~S}_{0.6}$ & 0.88 & 1.24 & 0.88 \\
\hline
\end{tabular}

The energy-dispersive spectra (EDS) further revealed that $\mathrm{Co}, \mathrm{Zn}$, and $\mathrm{O}$ exist in Co-based samples (Figure 2). Quantitative analysis of the atomic concentration (atom\%) is listed in Supplementary Table S1. It can be found that the Co content in the samples increased from 0.12 to 0.38 atom \%, based on the Co-doping levels. However, less Co 
was located in Co-doped $\mathrm{ZnO}$ crystallites than that provided in the precursor solution, indicating that some Co ions remain in the parent solution and do not become incorporated into the crystals. Furthermore, the band edge of the Co-doped ZnO sample-S0.8 shifted to the lower energy side, compared to the pure $\mathrm{ZnO}$ sample- $\mathrm{S}_{0}$ (Figure 2). The redshift phenomenon is mainly due to the $\mathrm{sp}-\mathrm{d}$ exchange interactions between the band electrons and the localized d electrons of the $\mathrm{Co}^{2+}$ cations. These results confirmed that the addition of Co did not change the $\mathrm{ZnO}$ structure.
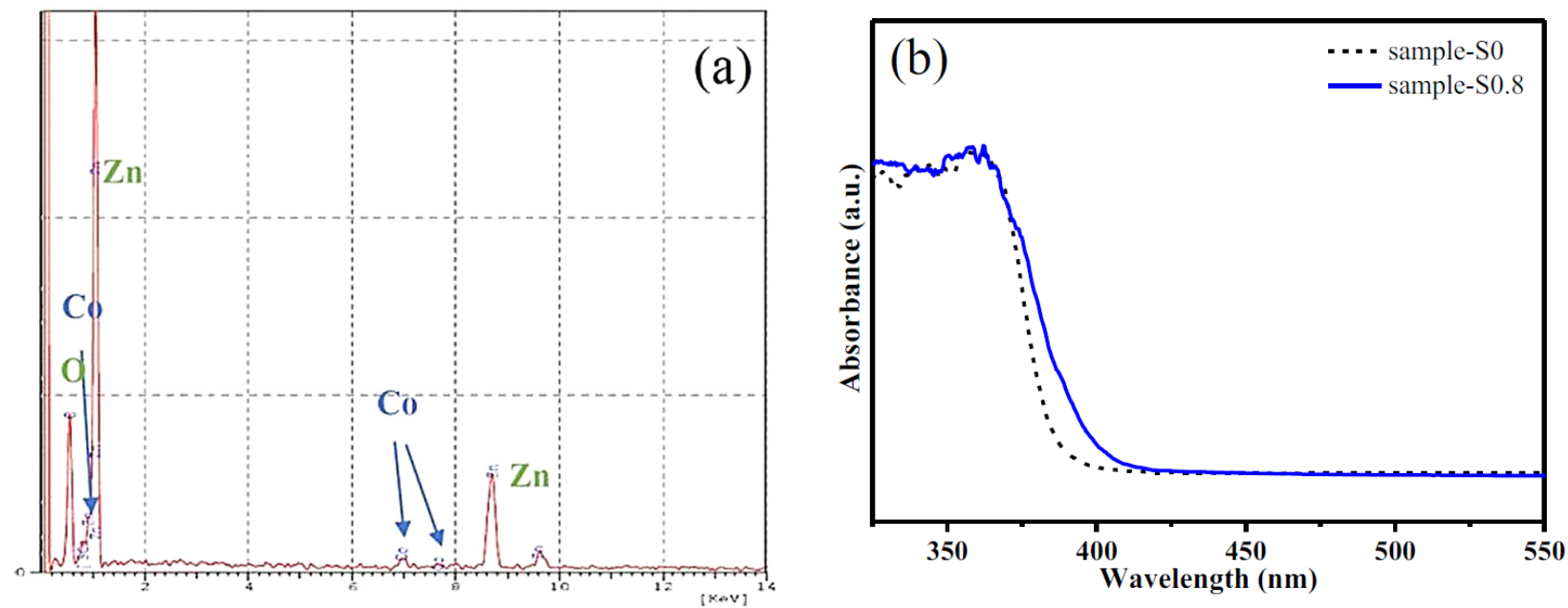

Figure 2. EDS (a) and UV (b) spectra of sample-S0.8.

\subsection{Morphological Characteristics}

From Figure $3 \mathrm{a}$, it is apparent that pure $\mathrm{ZnO}$ exhibits an olive-like morphology with an average size of about $400 \mathrm{~nm}$. With the addition of $\mathrm{Co}$, the obtained sample-S0.2 also showed an olive-like morphology with a length of about $500 \mathrm{~nm}$ (Figure 3b,c). On the other hand, the morphology of sample-S0.8 produced after Co-doping changed significantly, and was mostly flower-like nanoclusters with an average size of $500 \mathrm{~nm}$, which are comprised of much smaller nanorods (Figure 3d). Flower-like particles with enormous interface areas demonstrated good light-harvesting ability, and quickly transformed the light-generated charge in the photocatalytic processes, and had better catalytic ability than nanorods and nanoparticles [30]. These differences can be explained in terms of a thermodynamic barrier arising from the dopant $\left(\mathrm{Co}^{2+}\right)$ that slows the nucleation and inhibits further growth of $\mathrm{ZnO}$ around a doped nanocrystal.

\subsection{Mechanism}

\subsubsection{Effects of Reaction Temperature on the Morphology of Co-Doped ZnO Particles}

FESEM images of pure $\mathrm{ZnO}$ (sample- $\mathrm{S}_{0}{ }^{*}$ ), sample-S0.2* and sample-S0.8* are shown in Figure 4 . When the reaction temperature was increased to $70{ }^{\circ} \mathrm{C}$, the obtained $\mathrm{ZnO}$ particles of sample- $\mathrm{S}_{0}{ }^{*}$ with a size of about $90 \mathrm{~nm}$ were obtained, which is smaller than sample- $\mathrm{S}_{0}$ obtained at $50{ }^{\circ} \mathrm{C}(400 \mathrm{~nm}$, Figure $4 \mathrm{a})$. Higher temperature accelerates the growth process and allows the synthesis of small $\mathrm{ZnO}$ particles [31]. With the addition of $\mathrm{Co}$, the obtained sample-S0.2* and sample-S0.8* had a larger size of about $150 \mathrm{~nm}$, but a similar 1D rod-like morphology to sample- $S_{0}^{*}$ (Figure $4 \mathrm{~b}$ ). This is quite different from particles obtained at the reaction temperature of $50{ }^{\circ} \mathrm{C}$ when $3 \mathrm{D}$ particles are formed. Higher temperature accelerates the growth process but does not change the growth characteristics of Co-doped $\mathrm{ZnO}$ samples. The morphology of Co-doped $\mathrm{ZnO}$ particles seems more dependent on reaction temperature than the doped amount of $\mathrm{Co}$.

\subsubsection{Effects of Cobalt Counter-Ions on the Morphology of Co-Doped ZnO Particles}

Cobalt acetate tetrahydrate $\left(\mathrm{Co}\left(\mathrm{CH}_{3} \mathrm{COO}\right)_{2} \cdot 4 \mathrm{H}_{2} \mathrm{O}, 0.2 \mathrm{~mol} \% \mathrm{Co}: \mathrm{ZnO}\right)$ was also used as the Co source, and sample-C50 and sample-C70 were obtained when the reaction 
temperature was 50 and $70^{\circ} \mathrm{C}$, respectively. Figure 5a shows that when cobalt acetate tetrahydrate was used as the Co source instead of cobaltous chloride hexahydrate, flowerlike particles composed of olives were produced (sample-C50, $50{ }^{\circ} \mathrm{C}$ ). Interestingly, the flower-like particles of about $800 \mathrm{~nm}$ were larger than in sample-S0.8, which was obtained under nearly the same conditions, except for the amount of $\mathrm{Co}(0.8 \mathrm{~mol} \% \mathrm{Co}: \mathrm{ZnO})$. When the reaction was increased to $70{ }^{\circ} \mathrm{C}$, rod-like particles similar to sample-S0.8* were obtained (sample-C70, Figure 5b). These results show that the cobalt counter-ion mainly affects the size of Co-doped $\mathrm{ZnO}$ particles.
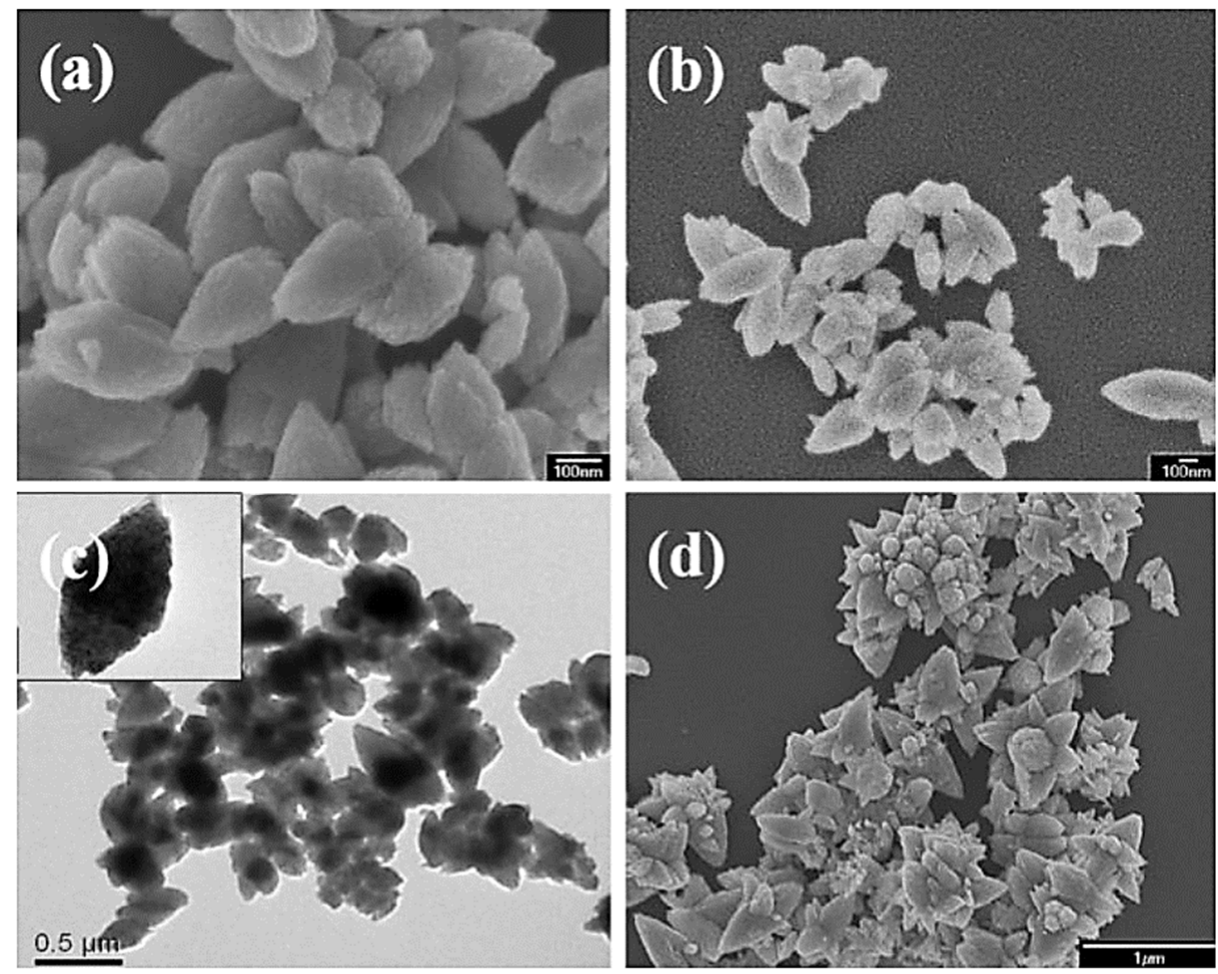

Figure 3. FESEM and TEM images of pure ZnO sample-S0 (a), and Co-doped sample-S0.2 (b,c) and sample-S0.8 (d).
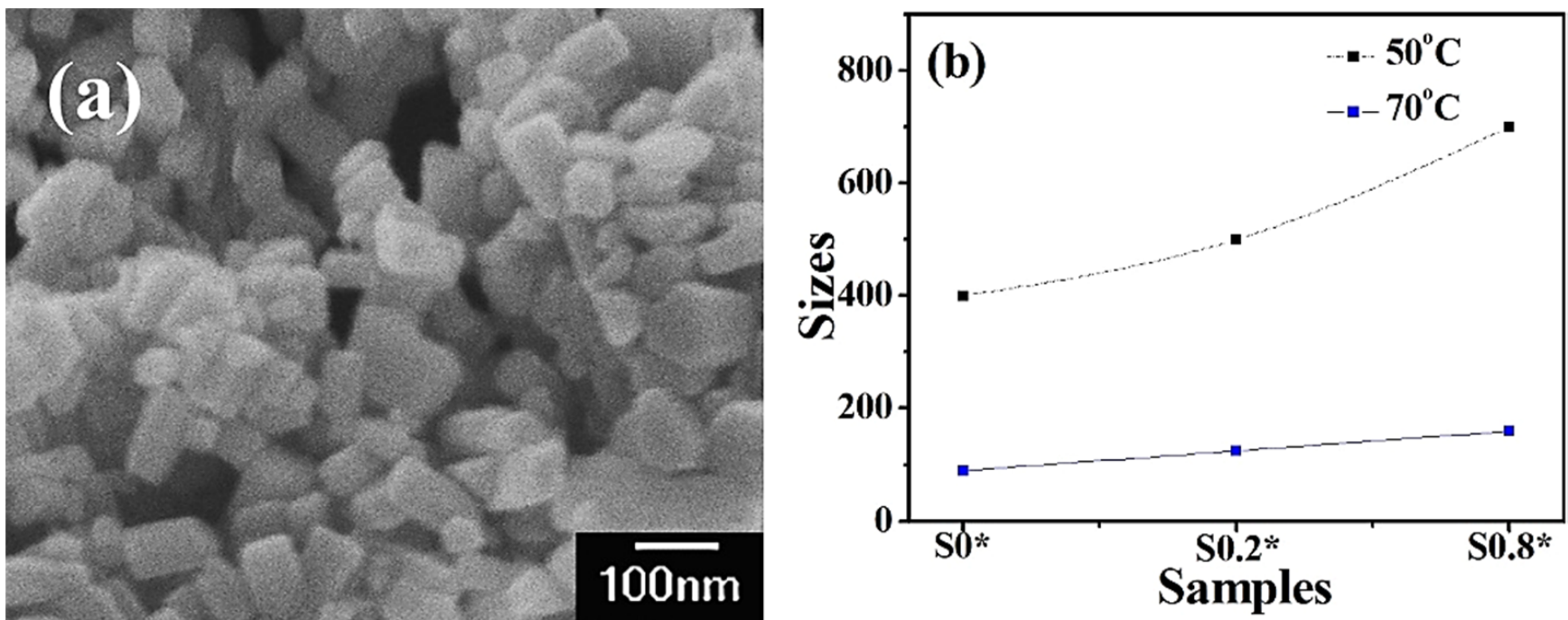

Figure 4. FESEM image of pure $\mathrm{ZnO}((\mathbf{a})$ sample-S0*), and (b) the size distributions of sample-S0.2* and sample-S0.8*. 

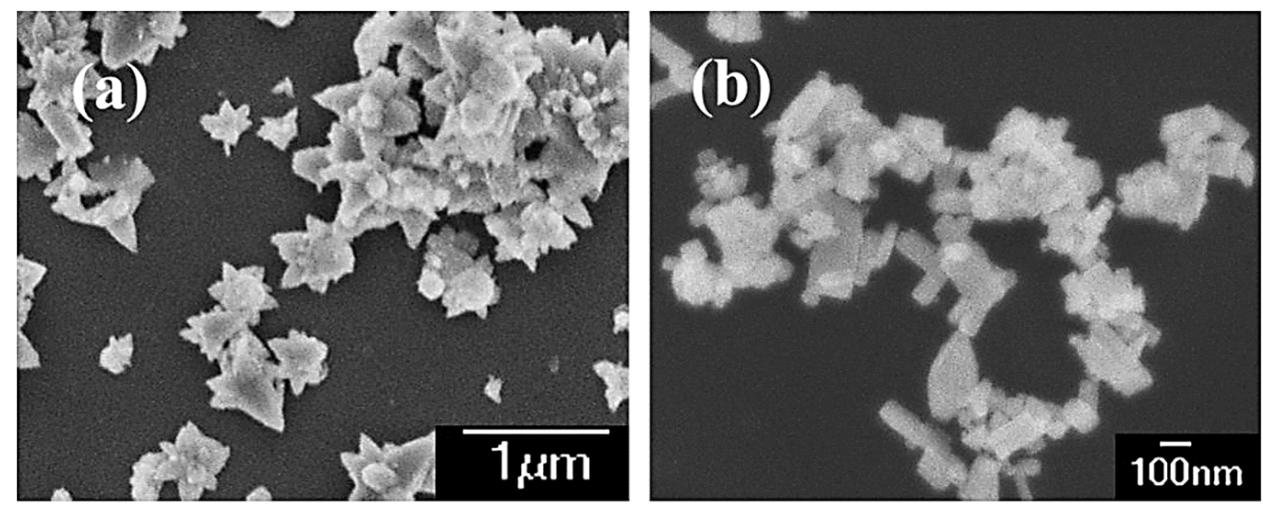

Figure 5. FESEM images of sample-C0.8\#50 (a) and sample-C0.8\#70 (b).

\subsubsection{Photocatalytic Activity}

The photochemical reactivity of $\mathrm{ZnO}$-based composites could be used for oxidative degradation of a variety of emerging contaminants, such as pharmaceuticals associated with toxicological impacts to aquatic environments [32]. The photochemical reactivity of Codoped $\mathrm{ZnO}$ catalysts synthesized with different molar ratios of $\mathrm{Co}^{2+}$ to $\mathrm{Zn}^{2+}$ for degradation of MB has been performed under UV light irradiation at room temperature. Figure $6 \mathrm{a}$ shows that blank $\mathrm{ZnO}$ enables a near $52 \%$ degradation rate of $1 \mathrm{mg}$ of $\mathrm{MB}$ with $150 \mathrm{~min}$ of UV light irradiation. With the addition of $\mathrm{Co}(0.2 \mathrm{~mol} \% \mathrm{Co}: \mathrm{ZnO})$, the photocatalytic activity of the obtained sample-S0.2 was lower than the blank, and about $34 \%$ of the $1 \mathrm{mg}$ of MB was degraded (Figure $6 \mathrm{~b}$ ). Further increasing the amount of $\mathrm{Co}$, the photocatalytic degradation rate of the obtained samples gradually decreased from $20 \%$ (sample-S0.4, Figure $6 \mathrm{c}$ ) to $18 \%$ (sample-S0.6, Figure 6d), and eventually to 16\% (sample-S0.8, Figure 6e). In our previous work, samples with different morphologies displayed a large difference in activities, and flower-like $\mathrm{ZnO}$ showed the best photodegradation rates [11]. However, flower-like Co-doped $\mathrm{ZnO}$ composites had the worst photodegradation rates in this work, which is probably because of the addition of Co. The kinetic model is discussed here to better understand the photocatalytic activity of synthesized photocatalysts. In general, the kinetics of photocatalytic degradation of organic pollutants on the semiconducting oxide has been established and can be well-described by the apparent first-order reaction, $\ln \left(\mathrm{C}_{0} / \mathrm{C}_{\mathrm{t}}\right)=k_{\text {app }} t$, where $k_{\text {app }}$ is the apparent rate constant, $\mathrm{C}_{0}$ is the concentration of dyes after darkness adsorption for $30 \mathrm{~min}$, and $\mathrm{C}_{\mathrm{t}}$ is the concentration of dyes at time t. Supplementary Figure S1 shows the relationship between illumination time and the degradation rate of dyes for UV illumination. The linear correlation of the plots of $\ln \left(C_{0} / C_{t}\right)$ versus time suggests a pseudo-first-order reaction for MB dye.

The photochemical reactivity of sample- $\mathrm{S}_{0}$, sample-S0.2, sample- $\mathrm{S}_{0}{ }^{*}$, and sample-S0.2* was performed under UV light irradiation at room temperature. From Supplementary Figure $\mathrm{S} 2$, it is obvious that blank $\mathrm{ZnO}$ (sample- $\mathrm{S}_{0}$ ) obtained at $50{ }^{\circ} \mathrm{C}$ had better photocatalytic activity than that produced at $70{ }^{\circ} \mathrm{C}$ (sample- $\left.\mathrm{S}_{0}{ }^{*}\right)$. With the addition of $\mathrm{Co}(0.2 \mathrm{~mol} \%$ $\mathrm{Co}: \mathrm{ZnO})$, the photocatalytic activity of the obtained sample-S0.2 and sample-S0.2* was lower than their corresponding blanks. Furthermore, sample-S0.2* showed a worse photocatalytic activity, and about $25 \%$ of $1 \mathrm{mg}$ of $\mathrm{MB}$ was degraded under UV light irradiation for $150 \mathrm{~min}$.

Sample-S0.2 was taken as a typical sample to study the degradation process. Supplementary Figure S3 shows the variances in the absorbance of MB with sample-S0.2 as the photocatalyst. The prominent absorption peak centered at $663 \mathrm{~nm}$, and no blue- or redshifts were observed during the photocatalytic procedure, implying that the decolorating process for $\mathrm{MB}$ is not ascribed to the $\mathrm{N}$-demethylation [33]. Furthermore, after irradiation for $150 \mathrm{~min}$, the discoloration of MB aqueous solution was apparent (see the inset in Supplementary Figure S2). 


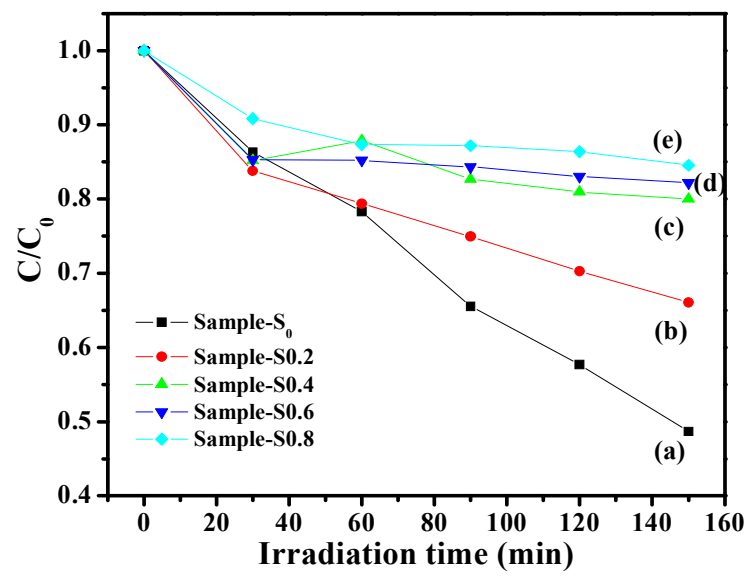

Figure 6. Extent of decomposition of the $\mathrm{MB}$ dye with respect to time intervals over $\mathrm{ZnO}$ (sample$\mathrm{S}_{0}(\mathbf{a})$, and Co-doped ZnO photocatalysts: sample-S0.2 (b), sample-S0.4 (c), sample-S0.6 (d), and sample-S0.8 (e), under UV irradiation.

We also evaluated these samples' photocatalytic hydrogen evolution activities (Figure 7). Pure $\mathrm{ZnO}$ exhibited the best $\mathrm{H}_{2}$ production ability of about $50 \mu \mathrm{mol} \mathrm{g}^{-1}$ for $4 \mathrm{~h}$ (sample- $\mathrm{S}_{0}$ ). Furthermore, the $\mathrm{H}_{2}$ production rate also depends on the amount of $\mathrm{Co}$. After doping with different mole fractions of $\mathrm{Co}$, the photocatalytic $\mathrm{H}_{2}$ production rate significantly decreased. The lowest $\mathrm{H}_{2}$ production rate reached around $5.0 \mu \mathrm{mol} \mathrm{h}^{-1} \mathrm{~g}^{-1}$ over sample-S0.8, much lower than that over sample- $\mathrm{S}_{0}$. The results suggest that doping Co into $\mathrm{ZnO}$ is not practical for enhancing the $\mathrm{H}_{2}$ production rate.

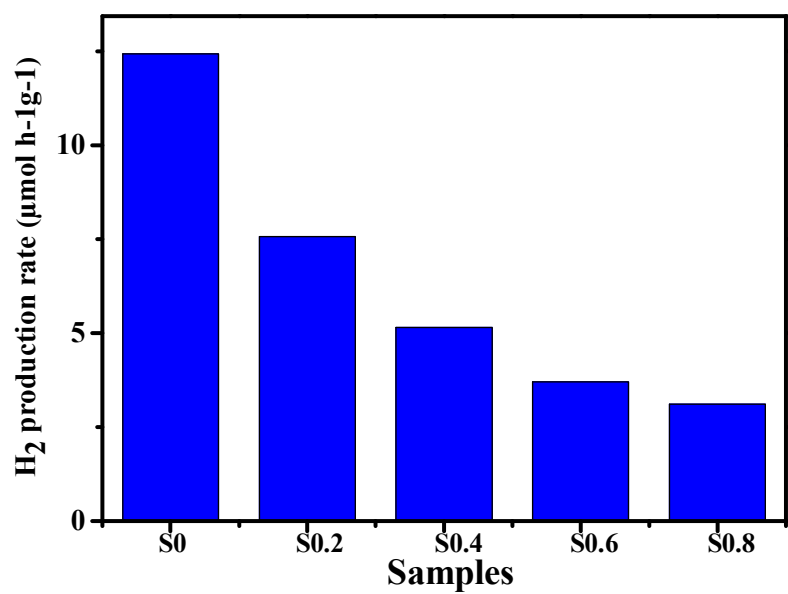

Figure 7. $\mathrm{H}_{2}$ evolution over $\mathrm{ZnO}$ (sample- $\mathrm{S}_{0}$ ), and Co-doped $\mathrm{ZnO}$ photocatalysts: sample-S0.2, sample-S0.4, sample-S0.6, and sample-S0.8.

It is known that illumination of the semiconductor material with a photon flux of energy greater than the bandgap width causes absorption of photons and generation of additional electron-hole pairs. As a result of the generation, an increase in the concentration of the excess electrons in the conduction band and the extra holes in the valence band occurs. The photocatalytic activity depends not only on intrinsic crystallographic structures of photocatalysts but also on the separation of the electron-hole pairs [34]. The transient photocurrent response of the prepared samples was measured to examine the charge separation and migration properties. In this way, the separation of electron-hole pairs generated by light absorption gives rise to a photocurrent. The photo-response curves were measured with light on/off cycles at $0 \mathrm{~V}$ versus SEC (saturated calomel electrode). The pure $\mathrm{ZnO}$ exhibited a fast and uniform photocurrent response for each light-on and light-off process, and the photocurrent density of the $\mathrm{ZnO}$ electrode was detected as $3.3 \mu \mathrm{A} / \mathrm{cm}^{2}$ (Figure 8a). However, the photocurrent density dramatically decreased by about $50 \%$ after 
loading Co to $\mathrm{ZnO}$ (Figure $8 \mathrm{~b}$ ). The observed decrease in photocurrent intensity could be ascribed to combining the photo-generated electron-hole pairs with defects' formation by loading $\mathrm{Co}$ to $\mathrm{ZnO}$. The ionic radii of $\mathrm{Co}$ and $\mathrm{Zn}$ are close to each other. The mechanism of reducing photocatalytic activity by Co-doping is therefore not considered to be by creating physical defects. The efficient recombination centers for photo-generated excitons would be the deep bandgap energy levels between the valence and conduction bands [35]. The results well-parallel the photocatalytic performances for dye degradation and $\mathrm{H}_{2}$ production.

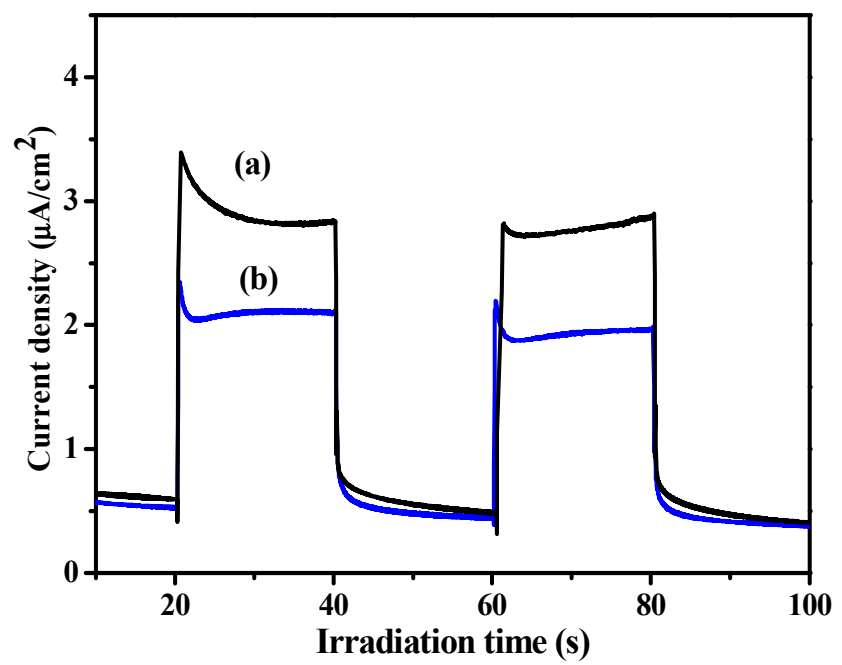

Figure 8. Photocurrent responses of $\mathrm{ZnO}$ (a) and Co-doped sample-S0.8 (b).

\section{Conclusions}

Co-doped $\mathrm{ZnO}$ particles directly from aqueous solutions at a low temperature $\left(50{ }^{\circ} \mathrm{C}\right)$ have been successfully synthesized via a simple one-step solution route. The effects of Co-doping, reaction temperature, and Co counter-ions on the structural, morphological, and photocatalytic properties of doped $\mathrm{ZnO}$ particles were investigated. XRD spectra indicated that cobalt ions, in the oxidation state of $\mathrm{Co} 2 p$, substitute $\mathrm{Zn} 2 p$ ions in the $\mathrm{ZnO}$ lattice without changing its wurtzite structure. According to the EDS spectra, the dopant content varied from $0.12 \%$ to $0.38 \%$, depending on Co-doping levels. The reaction temperature and doped amount of Co significantly affected the morphology of doped $\mathrm{ZnO}$ particles. Pure ZnO exhibited an olive-like morphology, and the Co-ZnO particles took on the shape of olive-like and eventually flower-like nanoclusters depending on the amount of Co. The optical property of doped $\mathrm{ZnO}$ particles is determined by $\mathrm{H}_{2}$ evolution and the degradation of MB. The photocurrent intensity test proved the formation of recombination centers, leading to the reduction of photocatalytic activity of the Co-doping samples. This work showed that doping is a double-edged sword, and attention should be paid not only to the doping itself but also the doping species. Further work can focus on the study of serial doping metal ions and the regulations of the structural and catalytic properties.

Supplementary Materials: The following supporting information can be downloaded, Figure S1: Apparent rate constants of $\mathrm{MB}$ dye in the presence of $\mathrm{ZnO}$ (sample-S0, a) and Co-doped $\mathrm{ZnO}$ photocatalysts: sample-S0.2 (b), sample-S0.4 (c), sample-S0.6 (d), and sample-S0.8 (e) under UV irradiation.; Figure S2: Extent of decomposition of the MB dye with respect to time intervals over pure $\mathrm{ZnO}$ sample-S0 and sample-S0* (a,c), and Co-dopped ZnO photocatalysts: sample-S0.2 (b), and sample-S0.2* (d) under UV irradiation.; Figure S3: The absorbance of MB with sample-S0.8 as a function of irradiation time. Table S1: The composition of $\mathrm{ZnO}$ nanocrystals dependence on Co-doping levels.

Author Contributions: Validation, Y.J., Z.Z. (Zhishang Zhu), Y.H. and J.W.; investigation, Y.J., Z.Z. (Zhishang Zhu) and Y.H.; writing-review and editing, L.T.; funding acquisition, L.T., Y.Z. and Z.Z. (Zhigang Zou). All authors have read and agreed to the published version of the manuscript. 
Funding: This work was supported by the Major Research Plan of the National Natural Science Foundation of China (2018YFE0208500), the NSF of China (21773114, 21603183, 21473091), the NSF of Jiangsu Province (BK2012015 and BK20130425), the Key Laboratory for Advanced Technology in Environmental Protection of Jiangsu Province (JBGS004).

Institutional Review Board Statement: Not applicable.

Informed Consent Statement: Not applicable.

Data Availability Statement: The data presented in this study are available in Supplementary Materials.

Conflicts of Interest: The authors declare no conflict of interest.

Sample Availability: Samples of the compounds are not available from the authors.

\section{References}

1. Perera, F. Pollution from Fossil-Fuel Combustion is the Leading Environmental Threat to Global Pediatric Health and Equity: Solutions Exist. Int. J. Environ. Res. Public Health 2017, 15, 16. [CrossRef] [PubMed]

2. Majumder, S.; Chatterjee, S.; Basnet, P.; Mukherjee, J. ZnO based nanomaterials for photocatalytic degradation of aqueous pharmaceutical waste solutions-A contemporary review. Environ. Nanotechnol. Monit. Manag. 2020, 14, 100386-100401. [CrossRef]

3. Meldrum, F.; Cölfen, H. Controlling Mineral Morphologies and Structures in Biological and Synthetic Systems. Chem. Rev. 2008, 108, 4332-4432. [CrossRef] [PubMed]

4. Li, H.; Gu, S.; Sun, Z.; Guo, F.; Xie, Y.; Tao, B.; He, X.; Zhang, W.; Chang, H. In-built bionic "MoFe-cofactor" in Fe-doped two-dimensional $\mathrm{MoTe}_{2}$ nanosheets for boosting the photocatalytic nitrogen reduction performance. J. Mater. Chem. A 2020, 8 , 13038-13048. [CrossRef]

5. Li, H.; Deng, H.; Gu, S.; Li, C.; Tao, B.; Chen, S.; He, X.; Wang, G.; Zhang, W.; Chang, H. Engineering of bionic Fe/Mo bimetallene for boosting the photocatalytic nitrogen reduction performance. J. Colloid Interface Sci. 2022, 607, 1625-1632. [CrossRef] [PubMed]

6. Pietruszka, R.; Witkowski, B.S.; Gieraltowska, S.; Caban, P.; Wachnicki, L.; Zielony, E.; Gwozdz, K.; Bieganski, P.; Placzek-Popko, E.; Godlewski, M. New efficient solar cell structures based on zinc oxide nanorods. Sol. Energy Mater. Sol. Cells 2015, 143, 99-104. [CrossRef]

7. Momeni, K.; Attariani, H. Electromechanical properties of 1D ZnO nanostructures: Nanopiezotronics building blocks, surface and size-scale effects. Phys. Chem. Chem. Phys. 2014, 16, 4522-4527. [CrossRef]

8. Nandi, S.; Kumar, S.; Misra, A. Zinc oxide heterostructures: Advances in devices from self-powered photodetectors to selfcharging supercapacitors. Adv. Mater. 2021, 2, 6768-6799. [CrossRef]

9. Nanto, H.; Minami, T.; Takata, S. Zinc-oxide thin-film ammonia gas sensors with high sensitivity and excellent selectivity. J. Appl. Phys. 1986, 60, 482-484. [CrossRef]

10. Rahman, F. Zinc oxide light-emitting diodes: A review. Opt. Eng. 2019, 58, 010901. [CrossRef]

11. Sun, L.; Shao, R.; Chen, Z.; Tang, L.; Dai, Y.; Ding, J. Alkali-dependent synthesis of flowerlike ZnO structures with enhanced photocatalytic activity via a facile hydrothermal method. Appl. Surf. Sci. 2012, 258, 5455-5461. [CrossRef]

12. Rahmane, S.; Aida, M.S.; Djouadi, M.A.; Barreau, N. Effects of thickness variation on properties of ZnO: Al thin films grown by RF magnetron sputtering deposition. Superlattices Microstruct. 2015, 79, 148-155. [CrossRef]

13. Wu, J.-J.; Liu, S.-C. Low-Temperature Growth of Well-Aligned ZnO Nanorods by Chemical Vapor Deposition. Adv. Mater. 2002, 14, 215-218. [CrossRef]

14. Jin, B.J.; Bae, S.H.; Lee, S.Y.; Im, S. Effects of native defects on optical and electrical properties of ZnO prepared by pulsed laser deposition. Mater. Sci. Eng. 2000, 71, 301-305. [CrossRef]

15. Kripal, R.; Gupta, A.K.; Srivastava, R.K.; Mishra, S.K. Photoconductivity and photoluminescence of ZnO nanoparticles synthesized via co-precipitation method. Spectrochim. Acta Part A Mol. Biomol. Spectrosc. 2011, 79, 1605-1612. [CrossRef] [PubMed]

16. Wadaa, S.; Tsurumia, T.; Chikamorib, H.; Nomab, T.; Suzukib, T. Preparation of nm-sized BaTiO 3 crystallites by a LTDS method using a highly concentrated aqueous solution. J. Cryst. Growth 2001, 229, 433-439. [CrossRef]

17. Yazdanbakhsh, M.; Khosravi, I.; Goharshadi, E.K.; Youssefi, A. Fabrication of nanospinel $\mathrm{ZnCr}_{2} \mathrm{O}_{4}$ using sol-gel method and its application on removal of azo dye from aqueous solution. J. Hazard. Mater. 2010, 184, 684-689. [CrossRef]

18. Sun, X.; Li, Z.; Wang, X.; Zhang, G.; Cui, P.; Shen, H. Single-Crystal Regular Hexagonal Microplates of Two-Dimensional $\alpha$-Calcium Sulfate Hemihydrate Preparation from Phosphogypsum in $\mathrm{Na}_{2} \mathrm{SO}_{4}$ Aqueous Solution. Ind. Eng. Chem. Res. 2020, 59, 13979-13987. [CrossRef]

19. Boppella, R.; Anjaneyulu, K.; Basak, P.; Manorama, S.V. Facile Synthesis of Face Oriented ZnO Crystals: Tunable Polar Facets and Shape Induced Enhanced Photocatalytic Performance. J. Phys. Chem. C 2013, 117, 4597-4605. [CrossRef]

20. Tang, L.; Zhao, Z.; Zhou, Y.; Lv, B.; Li, P.; Ye, J.; Wang, X.; Xiao, M.; Zou, Z. Series of ZnSn(OH) 6 Polyhedra: Enhanced CO 2 Dissociation Activation and Crystal Facet-Based Homojunction Boosting Solar Fuel Synthesis. Inorg. Chem. 2017, 56, 5704-5709. [CrossRef] 
21. Li, P.; Zhou, Y.; Zhao, Z.; Xu, Q.; Wang, X.; Xiao, M.; Zou, Z. Hexahedron Prism-Anchored Octahedronal CeO ${ }_{2}$ : Crystal Facet-Based Homojunction Promoting Efficient Solar Fuel Synthesis. J. Am. Chem. Soc. 2015, 137, 9547-9550. [CrossRef] [PubMed]

22. Tang, L.; Vo, T.; Fan, X.; Vecchio, D.; Ma, T.; Lu, J.; Hou, H.; Glotzer, S.C.; Kotov, N.A. Self-Assembly Mechanism of Complex Corrugated Particles. J. Am. Chem. Soc. 2021, 143, 19655-19667. [CrossRef] [PubMed]

23. Xu, C.; Cao, L.; Su, G.; Liu, W.; Qu, X.; Yu, Y. Preparation, characterization and photocatalytic activity of Co-doped ZnO powders. J. Alloys Compd. 2010, 497, 373-376. [CrossRef]

24. Šutka, A.; Käämbre, T.; Pärna, R.; Juhnevica, I.; Maiorov, M.; Joost, U.; Kisand, V. Co doped ZnO nanowires as visible light photocatalysts. Solid State Sci. 2016, 56, 54-62. [CrossRef]

25. Xie, F.; Guo, J.; Wang, H.; Chang, N. Enhancing visible light photocatalytic activity by transformation of $\mathrm{Co}^{3+} / \mathrm{Co}^{2+}$ and formation of oxygen vacancies over rationally Co doped ZnO microspheres. Colloids Surf. A Physicochem. Eng. Asp. 2022, 636, 128157-128167. [CrossRef]

26. Chen, Z.; Fang, Y.; Wang, L.; Chen, X.; Lin, W.; Wang, X. Remarkable oxygen evolution by Co-doped ZnO nanorods and visible light. Appl. Catal. B-Environ. 2021, 296, 120369. [CrossRef]

27. Javed, A.; Shahzad, N.; Butt, F.; Khan, M.; Naeem, N.; Liaquat, R.; Khoja, A. Synthesis of bimetallic Co-Ni/ZnO nanoprisms (ZnO-NPr) for hydrogen-rich syngas production via partial oxidation of methane. J. Environ. Chem. Eng. 2021, 9, 106887-106899. [CrossRef]

28. Barret, C.S.; Massalski, T.B. Structure of Metals; Pergamon Press: Oxford, UK, 1980.

29. Romero, R.; Leinen, D.; Dalchiele, E.A.; Ramos-Barrado, J.R.; Martín, F. The effects of zinc acetate and zinc chloride precursors on the preferred crystalline orientation of $\mathrm{ZnO}$ and $\mathrm{Al}$-doped $\mathrm{ZnO}$ thin films obtained by spray pyrolysis. Thin Solid Film. 2006, 515, 1942-1949. [CrossRef]

30. Kubacka, A.; Fernandez-Garcia, M.; Colon, G. Advanced nanoarchitectures for solar photocatalytic applications. Chem. Rev. 2012, 112, 1555-1614. [CrossRef]

31. Pourrahimi, A.M.; Liu, D.; Ström, V.; Hedenqvist, M.S.; Olsson, R.T.; Gedde, U.W. Heat treatment of ZnO nanoparticles: New methods to achieve high-purity nanoparticles for high-voltage applications. J. Mater. Chem. A 2015, 3, 17190-17200. [CrossRef]

32. Olatunde, O.C.; Kuvarega, A.T.; Onwudiwe, D.C. Photo enhanced degradation of contaminants of emerging concern in waste water. Emerg. Contam. 2020, 6, 283-302. [CrossRef]

33. Zhang, T.; Oyama, T.; Aoshima, A.; Hidaka, H.; Zhao, J.; Serpone, N. Photooxidative N-demethylation of methylene blue in aqueous $\mathrm{TiO}_{2}$ dispersions under UV irradiation. J. Photochem. Photobiol. A Chem. 2001, 140, 163-172. [CrossRef]

34. Li, H.; Zhou, Y.; Tu, W.; Ye, J.; Zou, Z. State-of-the-Art Progress in Diverse Heterostructured Photocatalysts toward Promoting Photocatalytic Performance. Adv. Funct. Mater. 2015, 25, 998-1013. [CrossRef]

35. Mueller, T.; Malic, E. Exciton physics and device application of two-dimensional transition metal dichalcogenide semiconductors. NPJ 2D Mater. Appl. 2018, 2, 1-12. [CrossRef] 